\title{
PEMBUATAN PUPUK ORGANIK BERBAHAN LIMBAH KOTORAN SAPI UNTUK MENINGKATKAN PRODUKTIFITAS PERTANIAN WARGA DI DUSUN GENUK DESA SNEPO KEC SLAHUNG KAB. PONOROGO
}

\author{
Syaiful Arif \\ Fakultas Ushuluddin IAIN Ponorogo \\ Email: syaiful@iainponorogo.ac.id
}

\begin{abstract}
ABSTRAK
Modelpeternakan sapi diDusun Genuk Desa Senepo Kecamatan Slahung Kabupaten Ponorogo dikelola secara tradisional dan dalam skala kecil atau rumah tangga sehingga orientasi peternakan hanya mengedepankan produktivitas ternaknya dan belum memanfaatkan limbah kotoran sapi sebagai nilai tambah bagi peternak. Tujuan pengabdian yang kami lakukan adalab mengelola kotoran sapi agar bisamenjadi pupuk organik yang bisa digunakan oleh peternak. untuk. mengelola laban pertanian dan menekan biaya produksi pertanian selama ini. Metode yang digunakan dalam pengabdian ini adalah melakukan pelatihan dan praktik pembuatan pupuk organik bersama warga pemilik ternak dengan bekerjasama dengan dinaspertanian Kabupaten Ponorogo. Hasil dari pengabdian masyarakat ini msyarakat genuk bisa memproduksi pupuk organik secara mandiri atau berkelompok.
\end{abstract}

Kata kunci: Kotoran, Sapi, Limbah, Pupuk, Organik

\begin{abstract}
The beef farm model in the village village of senepo district is traditionally run and ona small scale or domestic so that the farm's orientation is just a waste of productivity and has not yet used cow waste as an added value to the farmer. The aim of our devotion is to manage cow dung so that it can become an organic fertilizer that any farmer can use to manage the farm and to suppress the cost of farm production. The method used in this service is to provide organic training and practice of developing fertilizer with residents of livestock owners by working with the agricultural ministry of ponorogo district. As a result of this community's devotion the public can produce organic fertilizer independently or in groups.
\end{abstract}

Keywords: Dirt, Cows, Waste, Organic Fertilizer 


\section{PENDAHULUAN}

Sektor peternakan di kabupaten Ponorogo pada umumnya masih merupakan usaha rakyat dikembangkan di lingkungan pedesaan biasanya menggunakan teknologi yang sederhana dan berskala kecil. Usaha yang dikelola secara tradisional ini merupakan usaha sampingan yang dapat diartkan sebagai tabungan keluarga guna memenuhi kebutuhan dan dalam skala besar atau jumlah yang banyak. Pengembangan sektor peternakan tersebut sekarang ini diarahkan tidak hanya terkait dengan pemenuhan pangan namun juga berkaitan dengan kesehatan dan lingkungan. Intensifikasi usaha peternakan telah mencapai efisiensi produksi tetapi juga perlu melihat isu lingkungan, yang menjadi perhatian baik di negara maju dan berkembang. ${ }^{1}$ Dampak dari sektor ini pada pencemaran lingkungan (amonia, gas rumah kaca dan patogen), mengevaluasi resiko kesehatan terkait dan menilai potensi peranan sistem pengolahan limbah dalam pelemahan isu-isu lingkungan dan kesehatan. ${ }^{2}$ Usaha peternakan baik yang dikelola secara skala kecil maupun skala besar menyumbangkan tingkat pencemaran pada lingkungan dari kotoran yang dihasilkan ternak tersebut.

Dusun Genuk Desa Senepo Kecamatan Slahung Kabupaten Ponorogo yang berada di daerah pegunungan yang banyak masyarakatnya memelihara hewan ternak yang didominasi oleh ternak sapi. Hampir setiap rumah yang ada di dusun ini memelihara sapi sebagai kegiatan sampingan warga selain bertani. Masyarakat genuk pada umumnya mata pencahariannya adalah dengan bertani di ladang terutama pada musim penghujan, jika musim kemarau tiba masyarakat lebih banyak kegiatannya dengan berternak. Model beternak yang di kelola warga Dusun Genuk di kelola secara tradisional, sehingga yang di ambil keuntungannya hanyalah hasil jualan hewan ternak yang sudah digemukkan dan akan digunakan untuk pemenuhan kebutuhan sehari hari.

Secara umum warga Dusun Genuk belum memanfaatkan limbah daripada peternakan yang ada. Kotoran sapi merupakan limbah dari peternakan warga, satu ekor sapi setiap harinya menghasilkan kotoran berkisar $8-10 \mathrm{~kg}$ per hari atau 2,6 - 3,6 ton per tahun atau setara dengan 1,5-2 ton pupuk organic sehingga akan mengurangi penggunaan pupuk anorganik dan mempercepat prosesperbaikan lahan. Potensi jumlah kotoran sapi dapat dilihat dari populasi sapi. Populasi sapi potong di Indonesia diperkirakan 10,8 juta ekor dan sapi perah 350.000 - 400.000 ekor dan apabila satu ekor sapi rata-rata setiap hari

\footnotetext{
1 Nizwar Syafa'at dan Pantjar Simatupang, “Kebijakan Pemantapan Ketahanan Pangan Nasional ke Depan,” JURNAL PANGAN 15, no. 2 (2006); Nommy Horas Thombang Siahaan, Hukum lingkungan dan ekologi pembangunan (Erlangga, 2004).

2 M. Yulianda Satya Putra, "2.1. Kebakaran Hutan dan Lahan di Perkebunan Kabupaten Pelalawan oleh,” t.t.; Ananto Kasworo dan Munifatul Izzati, "Daur Ulang Kotoran Ternak SebagaiUpaya Mndukung Peternakan SapiPotongYang Berkelanjutan di Desa Jogonayan Kecamatan Ngablak Kabupaten Magelang," 2013; Manihar Situmorang dkk., "Prosiding Seminar Nasional Biologi, 13 April 2013: Optimalisasi Penerapan Riset Biologi dalam Membangun Kemandirian Bangsa," t.t.
} 
menghasilkan 7 kilogram kotoran kering maka kotoran kotoran sapi kering yang dihasilkan di Indonesia sebesar 78,4 juta kilogram kering per hari. ${ }^{3}$ Potensi yang sangat besar untuk dikelola dan dimanfaatkan kembali oleh masyarakat. Limbah peternakan yang dihasilkan tidak lagi menjadi beban biaya usaha akan tetapi menjadi hasil ikutan yang memiliki nilai ekonomi tinggi dan bila mungkin setara dengan nilai ekonomi produk utama (daging). ${ }^{4}$

Kotoran sapi merupakan salah satu bahan potensial untuk membuat pupuk organik. ${ }^{5}$ Pupuk organik mempunyai berbagai manfaat yang besar bagi tanah memperbaiki struktur tanah, memperbesar kemampuan zat hara tanah, memperbesar kemampuan tanah dalam menahan dan menyerap air. Manfaat bagi petani mampu mengurangi biaya produksi dalam mengolah lahan pertanian, mengurangi pencemaran lingkungan. ${ }^{6}$

Berdasarkan latar belakang tersebut, perlu adanya pengelolaan limbah kotoran sapi yang dimiliki warga agar menjadi barang yang lebih bermanfaat, sehingga kotoran yang selama ini menjadi limbah lingkungan bisa dikelola menjadi pupuk organik yang bisa dimanfaatkan warga kembali untuk pemenuhan pupuk dalam bertani. Agar warga dusun genuk bisa mengelola kotoran sapi dengan benar maka penting untuk diberikan pelatihan pembuatan pupuk organik yang berbahan dasar dari kotoran sapi.

\section{METODE}

Kegiatan pengabdian masyarakat ini dilaksanakan pada bulan Juli 2019 di Dusun Genuk Desa Senepo Kecamatan Slahung Kabupaten Ponorogo dengan mitra kegiatan adalah warga Dusun Genuk yang dikemas dalam bentuk pelatihan dan praktek pembuatan pupuk organik berbahan dasar kotoran sapi. Agar pelaksanaan pelatihan pembuatan pupuk organik berjalan lancar metode kegiatan dirancang dengan beberapa tahapan antara lain: 1) Tahap perencanaan dan persiapan 2) Tahap pelaksanaan 3) tahap pengevaluasian.

Tahapan perencanaan dan persiapan diantaranya adalah melakukan koordinasi

3 Krisno Budiyanto, “Tipologi Pendayagunaan Kotoran Sapi dalam Upaya Mendukung Pertanian Organik di Desa Sumbersari Kecamatan Poncokusumo Kabupaten Malang," Jurnal GAMMA, 7, no. 1 (2011): 42-49.

4 Rotua Kristin Simamora dan Rudi Salam Sinaga, "Peran Pemerintah Daerah dalam Pengembangan Pariwisata Alam dan Budaya di Kabupaten Tapanuli Utara," JPPUMA Jurnal Ilmu Pemerintahan dan Sosial Politik Universitas Medan Area 4, no. 1 (2016): 79-96; Bambang Sudiarto, "Pengelolaan Limbah Peternakan terpadu dan Agribisnis yang Berwawasan Lingkungan,” 2008.

5 Budiyanto, "Tipologi Pendayagunaan Kotoran Sapi dalam Upaya Mendukung Pertanian Organik di Desa Sumbersari Kecamatan Poncokusumo Kabupaten Malang."

6 Sukamto Hadisuwito, Membuat pupuk organik cair (AgroMedia, 2012); Pinus Lingga, Petunjuk penggunaan pupuk (Niaga Swadaya, 2001); Ayub S. Pranata, Meningkatkan hasil panen dengan pupuk. organik (AgroMedia, 2010). 
dengan warga mitra khususnya kepala Dusun Genuk dan ketua RT dingkungan dusun Genuk, untuk menentukan kesepakatan tentang waktu dan lokasi pelaksanaan kegiatan. Pada tahap ini pula disiapkan berbagai keperluan administrasi terutama koodinasi dengan dinas pertanian sebagai mitra kerjasama untuk menjadi narasumber pada pelatihan tersebut dan menyiapkan berbagai bahan dan alat pendukung kegiatan pelatihan.

Tahapan pelaksanaan kegiatan diantaranya adalah memberikan penyuluhan tentang bahaya penggunaan bahan kimia sebagai pupuk, pemanfaatan limbah pertanian menjadi berbagai pupuk organik, berbagai manfaat pupuk organik bagi tanaman dan tanah, yang terakhir praktik pembuatan pupuk organik berbagahan dasar kotoran ternak sapi. Tahap ketiga adalah melakukan monitoring dan evaluasi, tahap ini melakukan pengawasan terhadap proses pelatihan, sekaligus mencari berbagai permasalahan yang akan memungkinkan dihadapi.

\section{ANALISIS DAN PEMBAHASAN}

\section{Profil Dusun Genuk Desa Senepo Kec. Slahung Kab. Ponorogo}

Dusun Genuk merupakan salah satu dusun yang terletak di Desa Senepo Kecamatan Slahung Kabupaten Ponorogo. Sebagian besar wilayah Dusun Genuk terdiri dari persawahan. Dusun Genuk berada pada jarak kurang lebih 1 km dari kantor Dusun Genuk dan 30 km dari pusat Kota Ponorogo. Batas wilayah Dusun Genuk meliputi :

1. Batas Barat berbatasan dengan Desa Tugurejo

2. Batas Selatan berbatasan dengan Desa Mrayan,

3. Batas Timur berbatasan dengan Desa Slahung,

4. Batas utara berbatasan dengan Desa Tugurejo.

Secara geografis, luas wilayah Dusun Genuk sekitar 60 hektare yang di dalamnya terdapat 10 RT dan 04 RW. Kami menjangkau 4 RT dari Dusun Genuk, diantaranya adalah RT 01, RT 02, RT 03 dan RT 10. Jumlah penduduk di Dusun Genuk yang kita jangkau ialah sebagai berikut:

1. RT 01 sebanyak 34 Kepala Keluarga

2. RT 02 sebanyak 23 Kepala Keluarga

3. RT 03 sebanyak 26 Kepala Keluarga

4. RT 10 sebanyak 22 Kepala Keluarga

Dusun Genuk memiliki kepala keluarga dengan golongan ekonomi yang cukup. Dusun Genuk sendiri merupakan dataran tinggi yang mana sebagian besar wilayahnya merupakan persawahan dan perkebunan, sehingga mayoritas masyarakatnya bekerja sebagai petani dan pekebun. Selain itu masyarakat juga bekerja sebagai pengumpul getah pinus yang dikelola oleh perhutani setempat. Disamping itu, masyarakat Dusun Genuk mempunyai hewan ternak yang dipelihara sendiri seperti, kambing, sapi dan ayam. 
Masyarakat Dusun Genuk mayoritas beragama Islam. Dusun Genuk dilengkapi dengan fasilitas ibadah diantaranya memiliki dua masjid yaitu berada di RT 02 bernama Masjid AL-Muttaqin, RT 03 bernama Masjid Syekh Muniroh. Dusun Genuk memiliki kelompok kesenian Gambyong dan Karawitan yang diikuti oleh anak-anak, remaja dan warga Dusun Genuk dengan nama grub seni karawitan Giri Mustiko Laras. Pada hari tertentu Kesenian Gambyong melakukan latihan di salah satu rumah warga Dusun Genuk yaitu dirumah Bapak Slamet. Kesenian Gambyong dan Karawitan tersebut sering tampil pada acara-acara di dalam Dusun Genuk. Kesenian Karawitan Dusun Genuk sudah sering tampil tidak hanya di Dusun Genuk, tetapi sudah pernah tampil di luar daerah Slahung. Pada saat Agustusan ataupun hajatan tidak jarang kelompok tersebut tampil.

Dusun Genuk memiliki empat sekolah yaitu TK yang bernama TK PGRI Senepo, SD yang bernama SDN 2 Senepo, MTs Al-Akbar dan MA Al-Akbar. Sekolah tersebut dilaksanakan setiap hari Senin sampai Sabtu, sedangkan hari Minggu libur. Selain itu, berdasarkan hasil wawancara bapak Kepala Dusun, warga Dusun Genuk pada umumnya sudah sadar pentingnya pendidikan terbukti sudah banyak yang menempuh pendidikan di luar Dusun Genuk misalnya di SMKN 1 Ponorogo, SMK 1 Slahung, dan SMPN 2 Slahung bahkan ada yang menempuh pendidikan di pesantren Darul Huda Mayak Ponorogo.

Pelayanan bidang kesehatan yang ada di Dusun Genuk yaitu Posyandu Balita yang bernama Poslita dan Posyandu Lansia yang bernama Polansia, posyandu balita diselengarakan setiap satu bulan sekali, sedangkan posyandu lansia diselenggarakan setiap tiga bulan sekali. Posyandu tersebut dikelola oleh Bidan Desa Senepo.

Pada bidang olahraga, Dusun Genuk memiliki fasilitas untuk olahraga yaitu memiliki dua lapangan voly yang berada di RT 01 dibelakang rumah bapak Jarwan selaku kamituwo dan RT 02 berada di halaman rumah RT setempat. Warga sangat antusias dengan adanya fasilitas yang ada, terbukti setiap sore setelah sholat ashar warga setempat bermain voly.

\section{Proses Pembuatan Pupuk Organik Berbahan Dasar Limbah Kotoran Sapi}

Kegiatan pelatihan dan penyuluhan pembuatan pupuk organik dilaksanakan sebagai berikut:

Peratama, menyiapkan berbagai bahan diantarnya: Bakteri Mikrobia / EM4, bekatul/ dedak, air, tetes/gula merah/gula putih, arang sekam, kotoran sapi, dolumit (Kapur). Selanjutnya menyiapkan berbagai alat yang digunakan antara lain: cangkul, ember, cikrak, pisau, sekrop, sorong, dan karung goni.

Kedua, proses pembuatannya adalah dengan mencampurkan EM4 sekitar $100 \mathrm{ml}$ dengan satu ember tetes atau larutan $1 \mathrm{~kg}$ gula diaduk sampai merata, tahapan ini bertujuan untuk menghasilkan bakteri atau microba yang bermanfaat untuk pembusukan kotoran, setelah pengadukan larutan dibiarkan sampai 15 hari dalam keadaan tertutup. 
Ketiga, mencampurkan kotoran sapi yang sudah kering dengan bekatul sebanyak $50 \mathrm{~kg}$. dan arang sekam dengan larutan EM4 yang sudah di diamkan selama 15 hari tersebut dengan mengaduknya sampai merata.

Kelima, adonan pada tahap ketiga yang sudah tercampur merata ditutup dengan karung goni agar proses fermentasi berlangung maksimal, proses ini berlangsung selama 15 hari.

Keenam, melakukan pengadukan setiap dua hari sekali adonan di atas agar proses fermentasi berlangsung maksimal.

Ketujuh, hasil adonan yang setiap dua hari di buka tersebut, pada hari ke 16 bisa dilakukan penggilingan agar bisa di kemas atau di simpan. Jika penggilingan tidak ada maka bisa dihaluskan dengan cara di tumbuk, agar mudah jika digunakan.

\section{Alur pembuatan pupuk organik berbahan limbah kotoran sapi}

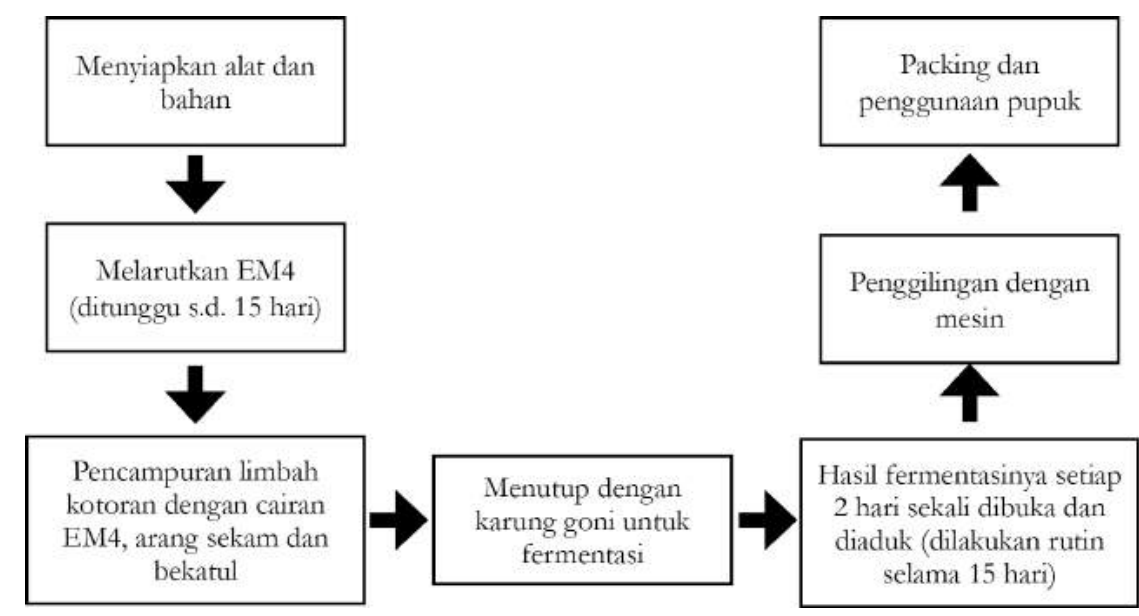

Pelaksanaan kegiatan berupa "Pembuatan Pupuk Organik Berbahan Limbah Kotoran Sapi di Dusun Genuk Desa Senepo Kecamatan Slahung Kabupaten Ponorogo" dilaksanakan pada hari Rabu, 31 Juli 2019 pukul 09.00-14.00 WIB di kediaman Bapak Slamet Riyadi (Ketua RT 10). Dalam kegiatan tersebut yang menjadi pemateri adalah Bapak Purwito SP. pelatihan ini dihadiri oleh tokoh masyarakat dan warga Dusun Genuk Desa Senepo Kecamatan Slahung. 


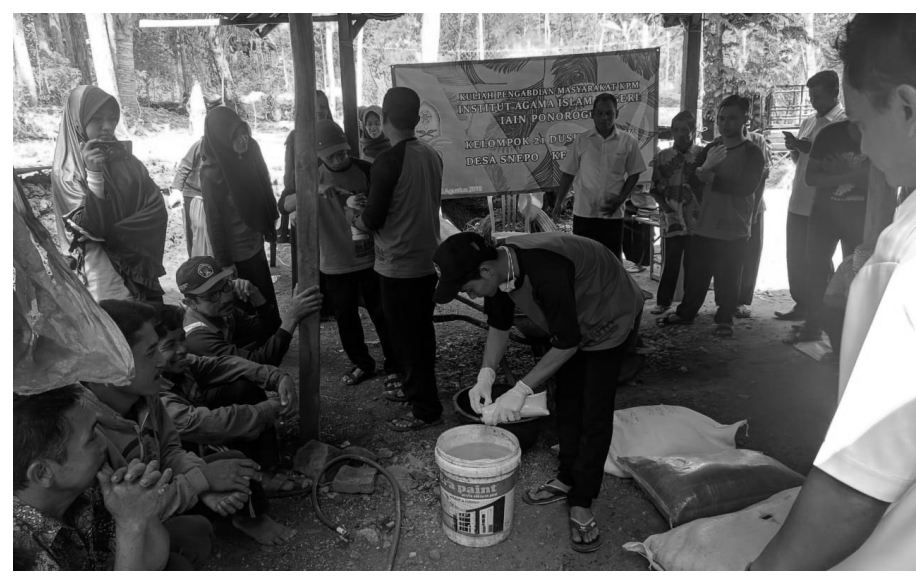

Gambar 1 Proses pelatihan

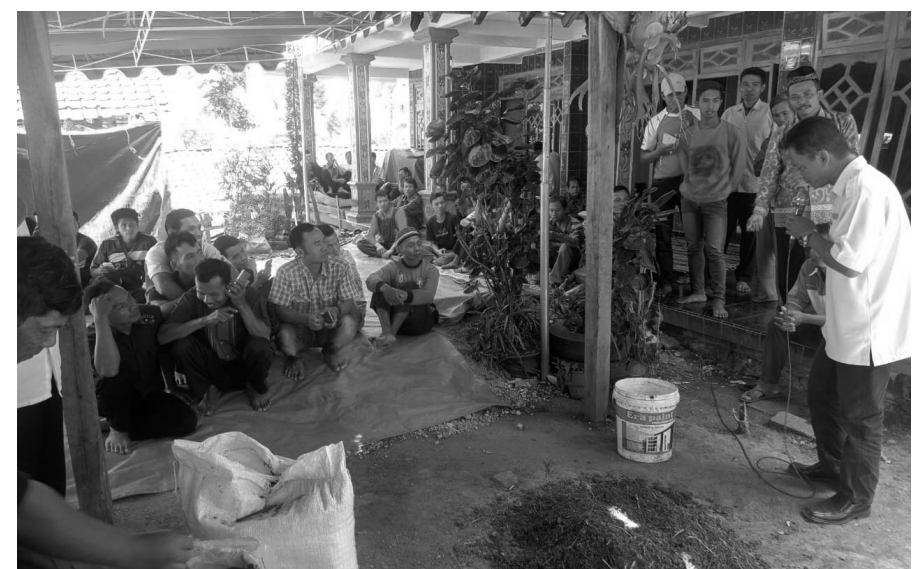

Gambar 2 Sosialisasi

\section{Dampak Lingkungan}

Sapi yang diternak baik skala kecil maupun besar tetap menghasilkan kotoran dan urine dalam jumlah yang cukup banyak jika hanya dibiarkan saja, alias berpotensi menjadi pencemaran lingkungan dan mengganggu jika tidak dikelola dengan segera. Salah satu kandungan kotoran sapi dan urine sapi adalah senyawa $\mathrm{NH}_{3}$, manakala berkondensasi dengan debu dalamkurun waktu yang lama akan menimbulkan penyakit bagi ternak dan tentunya daya tahan tubuh ternak akan turun sehingga kuwalitas sapi akan menurun. ${ }^{7}$

Melalui program pengabdian masyarakat ini diharapkan limbah kotoran sapi bisa diolah warga menjadi pupuk organik yang bisa di gunakan atau dimanfaatkan untuk bercocok tanam. Di samping itu lingkungan akan menjadi lebih sehat ternak juga tidak mudah terkena

Rama Prihandana, Energi bijau: Pilihan bijak menuju negeri mandiri energi (Niaga Swadaya, 2008); Agus Andoko dan S. S. T. Warsito, Beternak Kambing Unggul (AgroMedia, 2013). 
penyakit akibat limbah yang tidak dikelola atau dibiarkan saja. Melalui pemanfaatan limbah kotoran sapi dapat membangun hubungan yang muatualisme yang saling memanfaatkan secara positif.

\section{Dampak Sosial}

Secara umum 90\% warga tidak terganggu dengan pengelolaan ternak yang tradisional dan dilakukan di sekitar pemukiman masing masing. Namun jika dibiarkan dalam kurun waktu yang lama akan berdampak kesehatan dan sosial warga, dampak kesihatan yang berpotensi muncul adalah gangguan saluran pernapasan dan menurunnya daya tahan tubuh manusia. Dampak sosial yang dirasakan adalah bagi warga yang memang tidak suka dengan ternak sapi, karena berbagai alasan yang metarbelakanginya, tentunya akan menjadi masalah bagi warga tersebut. Potensi seperti ini berpeluang akan terjadi namun sangat kecil sekali, karena lahan pemukiman masih sangat luas.

\section{Dampak Ekonomi}

Pada saat pembersihan kandang, kotoran ternak akan ditumpuk di bagian belakang kandang bersama sisa pakan. Kotoran tersebut didiamkan saja dan sisa pakan yang tercampur dengan kotoran ternak agar menjadi busuk dan menjadi pupuk itupun jika berkenan menggunaknnya. ${ }^{8}$ Melalui pelatihan dalam program pengabdian masyarakat ini warga di ajak untuk minimal menekan biaya produksi pada waktu musim cocok tanam yang tentunya jika mengandalkan dari pupuk kimia akan menambah biaya produksi petani. Dengan biaya yang rendah petani bisa memperoleh untung karena pupuk bisa dibuat sendiri. Program pengabdian ini memang belum sampai menganalisis keuntungan jika dilakukan produksi dalam jumlah besar untuk memenuhi pansa pasar yang ada, sehingga keuntungan hanya dirasakan langsung oleh warga.

\section{Dampak Bagi Tanah}

Pupuk kandang memiliki sifat yang alami dan tidak merusak tanah, menyediakan unsur makro (nitrogen, fosfor, kalium, kalsium, dan belerang) dan mikro (besi, seng, boron, kobalt, dan molibdenium). ${ }^{9}$ Selain itu, pupuk kandang berfungsi untuk meningkatkan daya

\footnotetext{
8 Ir Maswarni dan Ir Nofiar Rachman, KUDA: Manajemen Pemeliharaan dan Pengembangbiakan (Penebar Swadaya Grup, t.t.); S. T. P. Harmono dan Agus Andoko, Budi Daya \& Peluang Bisnis Jahe (AgroMedia, 2005); Ir H. Irdika Mansur, Bisnis \& Budidaya 18 Kayu Komersial (Penebar Swadaya Grup, t.t.).

9 Yyuliana Yuliana, Elfi Rahmadani, Dan Indah Permanasari, “Aplikasi Pupuk Kandang Sapi dan Ayam Terhadap Pertumbuhan dan Hasil Tanaman Jahe (Zingiber officinale Rosc.) di Media Gambut," Jurnal Agroteknologi 5, no. 2 (2015): 37-42; Nining Dwi Ningsih, Neni Marlina, dan Erni Hawayanti, "Pengaruh Jenis Pupuk Organik terhadap Pertumbuhan dan Produksi Beberapa Varietas Jagung Manis (Zea mays saccharata Sturt)," Klorofil: Jurnal Penelitian
} 
tahan terhadap air, aktivitas mikrobiologi tanah, nilai kapasitas tukar kation dan memperbaiki struktur tanah. Pengaruh pemberian pupuk kandang secara tidak langsung memudahkan tanah untuk menyerap air. Pemakaian pupuk kandang sapi dapat meningkatkan permeabilitas dan kandungan bahan organik dalam tanah, dan dapat mengecilkan nilai erodobilitas tanah yang pada akhirnya meningkatkan ketahanan tanah terhadap erosi. Pupuk kandang dapat memberikan kontribusi hara yang mampu mencukupi pertumbuhan bibit tanaman, karena pupuk kandang mengandung hara yang lebih tinggi. ${ }^{10}$

Pupuk kandang sapi dan ayam memiliki efek terhadap kesuburan tanah gambut yang cukup baik karena mengandung unsur hara yang lengkap (makro dan mikro) serta mikroorganisme yang ada di dalamnya mampu menguraikan gambut menjadi lebih matang sehingga beberapa unsur hara dalam gambut seperti P mudah tersedia bagi tanaman. Dengan demikian, pupuk kandang akan memperbaiki kondisi fisik dan kesuburan gambut. ${ }^{11}$

\section{KESIMPULAN}

Berdasarkan observasi dalam kegiatan pengabdian yang kami lakukan di Dusun Genuk Desa Senepo Kecamatan Slahung kabupaten Ponorogo hampir setiap rumah memiliki sapi sebagai hewan ternak tentunya menghasilkan limbah kotoran dan urine yang cukup banyak, hal ini akan menimbulkan problematika jika tidak dikelola secara benar. Kenyataanya warga hanya menumpuk ketoran sapi di samping kanan atau kiri kandang kemudian dibiarkan, pada waktu tertentu jika dibutuhkan warga baru mengambil untuk dimanfaatkan. Melalui pelatihan yang diberikan ini warga mulai beraktifitas pengolahan limbah ternak sapi menjadi pupuk organik dengan memberikan beberapa perlakuan tertentu yang tidak rumit warga bisa mengambil manfaat dari kegiatan ini diantaranya, memberikan nilai tambah yang ekonomis, mengurangi pencemaran linkungan dan menambah zat hara dalam tanah.

Ilmu-Imu Pertanian 10, no. 2 (2015): 93-100; Edward Tacoh, A. Rumambi, dan W. B. Kaunang, "Pengaruh Pemanfaatan Pupuk Bokasi Feses sapi terhadap Produksi Sorgum Varietas Kawali," ZOOTEC 37, no. 1 (2016): 88-95.

10 YULIANA, RAHMADANI, dan PERMANASARI, "Aplikasi Pupuk Kandang Sapi dan Ayam Terhadap Pertumbuhan dan Hasil Tanaman Jahe (Zingiber officinale Rosc.) di Media Gambut"; Angga Riana dan Abdurrani Muin, "PENGGUNAAN CAMPURAN COCOPEAT DAN PUPUK KANDANG UNTUK PENANAMAN GAHARU (Aquilaria spP) PADA TANAH ULTISOL DI DESA PAK LAHENG KECAMATAN TOHO," JURNAL HUTAN LESTARI 5, no. 4 (t.t.); Santoso, Haryanti, dan Kadarsih, "Pengaruh pemberian pupuk kandang ayam terhadap pertumbuhan dan roduksi serat tiga klon rami di lahan aluvial Malang."

11 S. Najiyati, L. Muslihat, dan I.N.S Putra, Panduan Pengolahan Lahan Gambut untuk Pertanian Berkelanjutan (Bogor: Wetlands Internasional, 2005). 


\section{DAFTAR PUSTAKA}

Andoko, Agus, dan S. S. T. Warsito. (2013). Beternak Kambing Unggul. AgroMedia.

Budiyanto, Krisno. (2011). "Tipologi Pendayagunaan Kotoran Sapi dalam Upaya Mendukung Pertanian Organik di Desa Sumbersari Kecamatan Poncokusumo Kabupaten Malang," Jurnal GAMMA, 7 (1), pp. 42-49.

Hadisuwito, Sukamto. (2012). Membuat Pupuk Organik Cair. AgroMedia.

Harmono, S. T. P., dan Agus Andoko. (2005). Budi Daya \& Peluang Bisnis Jahe. AgroMedia.

Kasworo, Ananto, dan Munifatul Izzati. (2013). "Daur Ulang Kotoran Ternak Sebagai

Upaya Mendukung Peternakan Sapi Potong yang Berkelanjutan di Desa Jogonayan Kecamatan Ngablak Kabupaten Magelang".

Lingga, Pinus. (2001). Petunjuk penggunaan pupuk. Niaga Swadaya.

Mansur, Irdika. (t.t.). Bisnis \& Budidaya 18 Kayu Komersial. Penebar Swadaya Grup.

Maswarni dan Nofiar Rachman. (t.t.). KUDA: Manajemen Pemelibaraan dan Pengembangbiakan. Penebar Swadaya Grup.

Najiyati, S., L. Muslihat, dan I.N.S Putra. (2005). Panduan Pengolahan Laban Gambut untuke Pertanian Berkelanjutan. Bogor: Wetlands Internasional.

Ningsih, Nining Dwi, Neni Marlina, dan Erni Hawayanti. (2015). "Pengaruh Jenis Pupuk

Organik terhadap Pertumbuhan dan Produksi Beberapa Varietas Jagung Manis (Zea mays saccharata Sturt)." Klorofil: Jurnal Penelitian Ilmu-Imu Pertanian, 10 (2), pp. 93-100.

Pranata, Ayub S. (2010). Meningkatkan hasil panen dengan pupuk organik. AgroMedia.

Prihandana, Rama. (2008). Energi hijau: Piliban bijak menuju negeri mandiri energi. Niaga Swadaya.

Putra, M. Yulianda Satya. (t.t.). 2.1. Kebakaran Hutan dan Lahan di Perkebunan Kabupaten Pelalawan.

Riana, Angga, dan Abdurrani Muin. (t.t.). "Penggunaan Campuran Cocopeat Dan Pupuk Kandang Untuk Penanaman Gaharu (Aquilaria spp) Pada Tanah Ultisol Di Desa Pak Laheng Kecamatan Toho." JURNAL HUTAN LESTARI, 5 (4).

Santoso, B, F Haryanti, dan S.A Kadarsih. (2004). "Pengaruh Pemberian Pupuk Kandang Ayam terhadap Pertumbuhan dan Produksi Serat Tiga Klon Rami di Lahan Aluvial Malang", Jurnal Pupuk, 5 (2), pp. 14-18.

Siahaan, Nommy Horas Thombang. (2004). Hukum Lingkungan dan Ekologi Pembangunan. Erlangga.

Simamora, Rotua Kristin, dan Rudi Salam Sinaga. (2016). "Peran Pemerintah Daerah dalam Pengembangan Pariwisata Alam dan Budaya di Kabupaten Tapanuli Utara", JPPUMA Jurnal Ilmu Pemerintahan dan Sosial Politik. Universitas Medan Area, 4 (1), pp. 79-96.

Situmorang, Manihar, Hesti Wahyuningsih, Erni Jumilawaty, Saleha Hannum, Nunuk Priyani, dan T. Alief Aththorick. (2013). "Optimalisasi Penerapan Riset Biologi dalam Membangun Kemandirian Bangsa” dalam Prosiding Seminar Nasional Biologi.

Sudiarto, Bambang. (2008). Pengelolaan Limbah Peternakan terpadu dan Agribisnis yang 
Berwawasan Lingkungan.

Syafa'at, Nizwar, dan Pantjar Simatupang. (2006). "Kebijakan Pemantapan Ketahanan Pangan Nasional ke Depan" JURNAL PANGAN, 15 (2).

Tacoh, Edward, A. Rumambi, dan W. B. Kaunang. (2016). "Pengaruh Pemanfaatan Pupuk Bokasi Feses sapi terhadap Produksi Sorgum Varietas Kawali.” ZOOTEC, 37 (1), pp. 88-95.

Yuliana, Yuliana, Elfi Rahmadani, dan Indah Permanasari. (2015). “Aplikasi Pupuk Kandang Sapi dan Ayam Terhadap Pertumbuhan dan Hasil Tanaman Jahe (Zingiber officinale Rosc.) di Media Gambut" Jurnal Agroteknologi, 5 (2), pp. 37-42. 